\title{
Letter to the Editor Regarding 'An Investigation of the Skin Barrier Restoring Effects of a Cream and Lotion Containing Ceramides in a Multi-Vesicular Emulsion in People with Dry, Eczema-Prone Skin: The RESTORE Study Phase 1'
}

Anthony Vincent Rawlings · Majella E. Lane

Received: July 16, 2021 / Published online: October 17, 2021

(C) The Author(s) 2021

Dear Editor,

We read with great interest the publication of 'An investigation of the skin barrier restoring effects of a cream and lotion containing ceramides in a multi-vesicular emulsion in people with dry, eczema-prone skin: the RESTORE study phase 1 ' by Danby et al. [1]. This was a double-blind intra-subject study that compared the single application of five commercially available products (CeraVe lotion and cream, test products, versus Zerobase cream, Epimax cream and Aquamax cream products not vehicles) to a no treatment control site (NTC) on their dry lower legs. These authors reported that the test products offered superiority to other comparator products on sustaining clinically meaningful improvements in both hydration and skin dryness for $24 \mathrm{~h}$ over the NTC.

We have several concerns on the test methods used, the interpretation of the results and the ceramide nomenclature used in the publication.

This comment refers to the article available online at https://doi.org/10.1007/s13555-020-00426-3.

A. V. Rawlings ( $\square)$

AVR Consulting Ltd., Northwich, Cheshire, UK e-mail: tonyrawlings@avrconsulting.co.uk

A. V. Rawlings - M. E. Lane

Department of Pharmaceutics, University College

London School of Pharmacy, London, UK
1. Firstly, the study reports an investigation of the skin barrier restoring effects but traditional skin barrier measurements such as transepidermal water loss are not included in the study. Although skin capacitance measurements do give an indication of skin hydration, they are not a measure of barrier function improvements delivered by such products. The authors should consider the wipe off measures reported by others to discriminate skin hydration delivered by occlusion with such instruments [2, 3]. The skin capacitance measures give the expected hydration improvements for the test cream and lotion due to the presence of glycerol in the products based upon its dielectric constant. The comparator products would not be expected to deliver such increases in skin capacitance values as paraffin-containing products give low capacitance measurements [2-4]. As such the testing approach is not a good comparison for the products chosen.

2. The authors rightly recruited subjects with visible dryness on their legs with skin capacitance values of less than $35 \mathrm{AU}$. Indeed, starting values for all test sites are less than $30 \mathrm{AU}$. However, although improvements in skin capacitance are observed for the test products and they meet their primary objective outlined in the study protocol, the values decline after the 
3-h time point and remain in the zone of capacitance values defined for subjects having dry skin [5] especially after the 12-h measurement period for the subjects in the per protocol set. By this criterion using this instrument the skin is not moisturized enough to classify it as normal skin. As a result, the test products do not provide a sustained effect on skin hydration.

3 . The secondary outcome of differences in visual dryness was met but did not show any superiority to the comparator products until the 24-h period. However, although there are numerical differences in the extent of visual dryness reduction between the different products it appears there were no statistical differences between them.

4. 'Ceramides 1, 3 and 6-II' are reported to be included in the test products. This classification of ceramides is based upon the original chromatographic separation of ceramides that has now been replaced with the nomenclature classification approach of Motta et al. [6]. Farwick et al. reported that the Personal Care Products Council had adopted this system in 2009 for International Nomenclature of Cosmetic Ingredients (INCI) nomenclature to be consistent with the scientific literature [7]. More details on structure are given by Moore and Rawlings [8]. According to that nomenclature system, the test products contain ceramides EOP, NP and AP as described in Fig. 1. Scientifically, ceramide 1 is ceramide EOS not EOP which actually is ceramide 9 in the older numerical system [7]. In order to compare different publications of products containing ceramides, the older

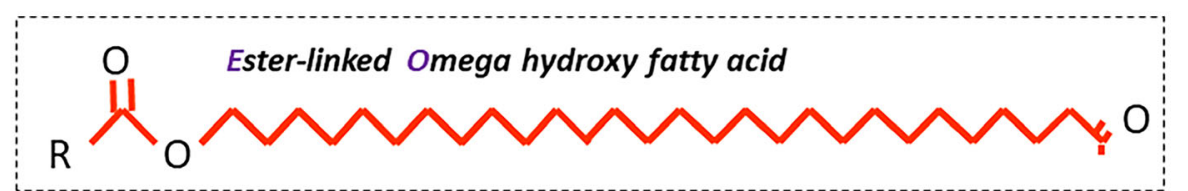

$$
\begin{aligned}
& \mathrm{R}=\mathrm{L} \text { : Linoleate } \\
& \mathrm{R}=\mathrm{O} \text { : Oleate } \\
& \mathrm{R}=\mathrm{S} \text { : Stearate } \\
& \text { e.g. CER EOS-L }
\end{aligned}
$$
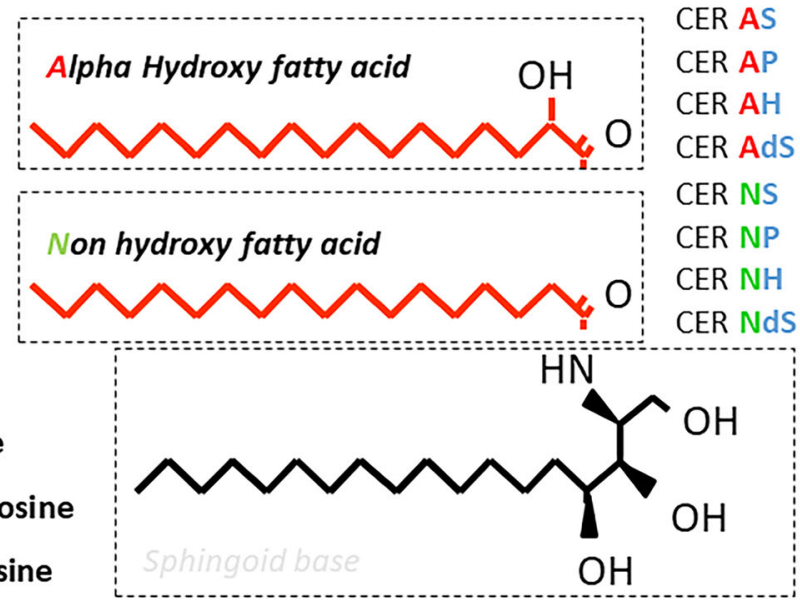

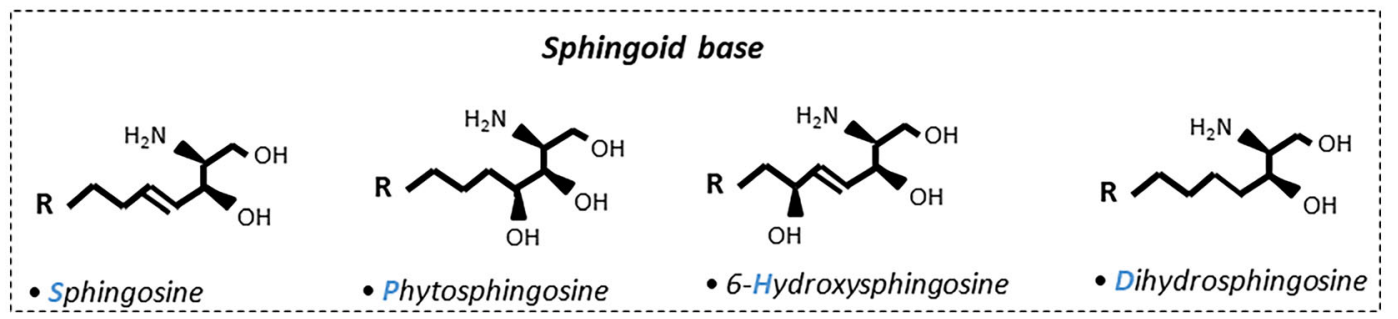

Fig. 1 Representation of the 12 most common ceramide classes. Permission has been granted to modify and republish Fig. 4 from the article, "Developments in
Ceramide Identification, Synthesis, Function and Nomenclature," published on Page 67 in Volume 124, No. 2 (February 2009) of Cosmetics \& Toiletries [7] 
nomenclature system should be discouraged from use in the dermatological literature for the more rigorous chemical classification. The reason for this is clear when the properties of the ceramides are compared. Stratum corneum lipid phase behaviour is completely different for ceramides EOS and EOP. Ceramide EOP/ceramide 9 reduces the formation of SC lipid long periodicity phase and is a weaker barrier compared with ceramide EOS $[9,10]$. Furthermore, we call for greater clarity for the types of fatty acids esterified to the omega-hydroxy groups of such acylceramides as these also dictate their behaviour [11]. In that nomenclature system linoleate $=\mathrm{L}$, oleate $=\mathrm{O}$ and stearate $=\mathrm{S}$, e.g. ceramide EOS-L (Fig. 1). In the current paper the type of fatty acid attached to ceramide EOP is not disclosed.

5. Interestingly, the authors state that it is the multi-vesicular nature of these products that dictates their efficacy because of a "controlled-release" mechanism. When a topical formulation is applied to the skin the physical act of rubbing will break down the microstructure of the product. Loss of volatile components also results in a residual phase remaining on the skin that is very different from the original product. Neither the authors nor the references cited provide any evidence that there is indeed such rate control for glycerol and skin lipids from the cream and lotion.

6. The test cream and lotion products contain a number of viscosity-modifying agents including xanthan gum, carbomer and sodium hyaluronate. These are absent in the comparator products. It is debatable if indeed the comparator products should have been selected for this study; more appropriate alternatives would confirm whether or not the test products are delivering significant benefits in terms of skin hydration. Indeed, data from an earlier publication has shown that when the test cream is compared with another glycerolcontaining but non-skin lipid/ceramidecontaining product its hydration efficacy is inferior as measured by skin conductance [12].

In conclusion, for the product comparisons there are uncertainties regarding the methodology used to demonstrate the occlusion benefits of the non-glycerol-containing products that may explain the comparable effects on visual dryness. Another glycerol-containing product shows superior efficacy. Also, more evidence is required to support a 'controlledrelease' claim for the skin lipids and glycerol. Moreover, in order to compare data in different publications there needs to be greater scientific clarity of the chemistry of ceramides used.

\section{ACKNOWLEDGEMENTS}

Compliance with Ethics Guidelines. This article is based on previously conducted studies and does not contain any new studies with human participants or animals performed by any of the authors.

Funding. No funding or sponsorship was received for this study or publication of this article.

Authorship. All named authors meet the International Committee of Medical Journal Editors (ICMJE) criteria for authorship for this article, take responsibility for the integrity of the work as a whole, and have given their approval for this version to be published.

Data Availability. Data sharing is not applicable to this article as no datasets were generated or analyzed during the current study.

Disclosures. Anthony V Rawlings currently consults for No7 Beauty Company (Member of Walgreens Boots Alliance), DSM Nutritional Products Limited, GlaxoSmithKline Consumer Healthcare Limited and Union Swiss. Majella E. Lane has nothing to disclose.

Open Access. This article is licensed under a Creative Commons Attribution-NonCommercial 4.0 International License, which permits 
any non-commercial use, sharing, adaptation, distribution and reproduction in any medium or format, as long as you give appropriate credit to the original author(s) and the source, provide a link to the Creative Commons licence, and indicate if changes were made. The images or other third party material in this article are included in the article's Creative Commons licence, unless indicated otherwise in a credit line to the material. If material is not included in the article's Creative Commons licence and your intended use is not permitted by statutory regulation or exceeds the permitted use, you will need to obtain permission directly from the copyright holder. To view a copy of this licence, visit http://creativecommons.org/licenses/by$\mathrm{nc} / 4.0 /$.

\section{REFERENCES}

1. Danby SG, Andrew PV, Brown K, Chittock J, Kay LJ, Cork MJ. An investigation of the skin barrier restoring effects of a cream and lotion containing ceramides in a multi-vesicular emulsion in people with dry, eczema-prone, skin: the RESTORE study phase 1. Dermatol Ther (Heidelb). 2020;10(5): 1031-41.

2. Loden $M$, Lindberg $M$. The influence of a single application of different moisturizers on the skin capacitance. Acta Derm Venereol. 1991;71(1): 79-82.

3. Loden M. The increase in skin hydration after application of emollients with different amounts of lipids. Acta Derm Venereol. 1992;72(5):327-30.
4. Crowther JM. Understanding effects of topical ingredients on electrical measurement of skin hydration. Int J Cosmet Sci. 2016;38(6):589-98.

5. Heinrich U, Koop U, Leneveu-Duchemin MC, et al. Multicentre comparison of skin hydration in terms of physical-, physiological- and product-dependent parameters by the capacitive method (Corneometer CM 825). Int J Cosmet Sci. 2003;25(1-2):45-53.

6. Motta S, Monti M, Sesana S, Caputo R, Carelli S, Ghidoni R. Ceramide composition of the psoriatic scale. Biochim Biophys Acta. 1993;1182(2):147-51.

7. Farwick M, Lersch P, Santonnat B, Korevaar K, Rawlings AV. Developments in ceramide identification, synthesis, function and nomenclature. Cosmet Toilet Mag. 2009;124(2):63-72.

8. Moore DJ, Rawlings AV. The chemistry, function and (patho)physiology of stratum corneum barrier ceramides. Int J Cosmet Sci. 2017;39(4):366-72.

9. de Jager M, Gooris G, Ponec M, Bouwstra J. Acylceramide head group architecture affects lipid organization in synthetic ceramide mixtures. J Invest Dermatol. 2004;123(5):911-6.

10. Opalka L, Kovacik A, Pullmannova P, Maixner J, Vavrova K. Effects of omega-O-acylceramide structures and concentrations in healthy and diseased skin barrier lipid membrane models. J Lipid Res. 2020;61(2):219-28.

11. de Sousa Neto D, Gooris G, Bouwstra J. Effect of the omega-acylceramides on the lipid organization of stratum corneum model membranes evaluated by X-ray diffraction and FTIR studies (Part I). Chem Phys Lipids. 2011;164(3):184-95.

12. Lee C, Bajor J, Moaddel T, et al. Principles of moisturizer product design. J Drugs Dermatol. 2019;18(1s):s89-95. 